\title{
Relationship between general nutrition knowledge and diet quality in Australian military personnel
}

\author{
Charina J. Kullen ${ }^{1,2 *}$, Jamie-Lee Farrugia ${ }^{3}$, Tania Prvan ${ }^{4}$ and Helen T. O'Connor ${ }^{2,5}$ \\ ${ }^{1}$ Australian Regular Army, Health Branch, HQ Forces Command, Paddington, NSW 2021, Australia \\ ${ }^{2}$ Faculty of Health Sciences, University of Sydney, Lidcombe, NSW 2141, Australia \\ ${ }^{3}$ Faculty of Science, University of Sydney, Darlington, NSW 2008, Australia \\ ${ }^{4}$ Department of Statistics, Faculty of Science and Engineering, Macquarie University, Sydney, NSW 2109, Australia \\ ${ }^{5}$ Charles Perkins Centre, University of Sydney, Camperdown, NSW 2006, Australia
}

(Submitted 4 August 2015 - Final revision received 10 December 2015 - Accepted 1 February 2016 - First published online 2 March 2016)

\section{Abstract}

A balanced diet informed by sound nutrition knowledge is key for operational readiness and the health of military personnel. Unfortunately, research suggests that military personnel have inadequate dietary intakes. This study assessed general nutrition knowledge, diet quality and their association in Australian military personnel. A convenience sample of male military personnel ( $n$ 211) including Army soldiers and officers completed a validated general nutrition knowledge questionnaire (GNKQ) and FFQ. The GNKQ assessed knowledge of dietary guidelines (Section A), sources of nutrients (Section B), choosing everyday foods (Section C) and diet-disease relationships (Section D). The Australian Recommended Food Score (ARFS) was used to assess diet quality from FFQ data. Statistical analyses included the $\chi^{2}$ test, Spearman's correlation test, $t$ test, median test, ANCOVA and ordinal logistic regression. The mean total GNKQ score was $52 \cdot 7 \%$. Participants performed best on Section A (58.5\%) followed by Sections B (57.3\%) and C (57.0\%) and worst on Section D (31.0\%). Overall, officers scored significantly higher than soldiers (58.7 v. 51.9\%, $P=0.001)$. Age was weakly but positively correlated with GNKQ total scores $(r 0.307 ; P<0.0005)$, with no significant effects seen for level of education $(P=0.463)$ or living arrangement $(P=0 \cdot 167)$. Overall ARFS was $37.6(\mathrm{sD} 7 \cdot 7)(50 \cdot 8 \%)$ with officers scoring significantly higher than soldiers $(54.7 v .50 \cdot 3 \%, P=0 \cdot 040)$. No demographic variables influenced total ARFS. The total GNKQ score had a significant, positive but weak relationship with total ARFS $(r 0.179 ; P=0.009)$. Given the importance of nutrition to personnel health and operational readiness, initiatives to improve nutrition knowledge and diet quality are recommended in this population, especially in soldiers.

Key words: Nutrition knowledge: Dietary intake: Diet quality: Military personnel

Adequate nutrition is fundamental to operational readiness for military personnel ${ }^{(1)}$. A healthy diet is therefore imperative for sustaining performance and optimising general health in this population $^{(2,3)}$. A wide range of individual (beliefs, knowledge, attitudes, skills and genetics), social (interaction with friends, family and community) and environmental factors are known to influence dietary intake ${ }^{(4-8)}$. Despite this complex network of influences, interventions designed to alter dietary behaviour in the military are typically designed around the manipulation of single factors such as improving nutrition knowledge or changing the food environment (e.g. dining hall programmes). Interventions aimed at increasing nutrition knowledge are particularly attractive as they are easy to implement; however, this approach is based on the assumption that increased knowledge translates to positive behaviour change.

Nutrition knowledge is reported to be influenced by a range of factors such as sex, age, level of education and socio-economic status. Previous studies have consistently found that men have a lower level of nutrition knowledge than women, a factor that may be related to women having a stronger interest in nutrition $^{(9-13)}$. Age is also an important demographic factor when assessing nutrition knowledge. Middle-aged individuals usually possess greater knowledge than younger and older participants in community ${ }^{(9,11)}$, athlete ${ }^{(14)}$ and military $\operatorname{groups}^{(13,15,16)}$. A positive relationship between nutrition knowledge and level of education is also evident across a number of studies in general community samples ${ }^{(9,11)}$. In studies of military personnel from the USA, rank ${ }^{(16)}$ and education ${ }^{(13)}$ have been shown to influence nutrition knowledge, with officers' nutrition knowledge reported as superior than that of soldiers. This relationship is not surprising, as a higher level of education is generally also associated with a range of other positive health behaviours or attributes, including a lower prevalence of smoking and obesity ${ }^{(9,17)}$.

Abbreviations: ARFS, Australian Recommended Food Score; GNKQ, general nutrition knowledge questionnaire.

* Corresponding author: C. J. Kullen, fax +61293519204, email ckul4586@uni.sydney.edu.au 
A number of studies have assessed the relationship between nutrition knowledge and dietary intake ${ }^{(14,18)}$. A recent systematic review from our group identified twenty-nine studies investigating the relationship between nutrition knowledge and dietary intake ${ }^{(18)}$. Of these studies, nineteen reported a significant, positive relationship between nutrition knowledge and dietary intake. However, these associations were generally weak $(r<0.5)$, with positive associations for nutrition knowledge most often reported for fruit and vegetable intakes. No studies have examined this relationship in military personnel. A number of weaknesses were identified in this review; importantly, nutrition knowledge and dietary intake were often not measured using validated instruments or methodology. The overall study quality ranged widely, and there was a low representation from men, with only $23 \%$ of the participants in the combined study sample being male.

Although no studies linking nutrition knowledge and food intake have been conducted in military personnel, numerous studies $^{(19-25)}$ have reported dietary intake in this population to be inconsistent with public health and/or military nutrition recommendations. Characteristics of studies reporting poor dietary intake in this population include excessive consumption of fat, particularly SFA, unbalanced eating patterns with increased serves of 'extras' or 'treat' foods and inadequate fruit, vegetable and whole-grain consumption. Some studies report substantially low intakes of certain nutrients including $\mathrm{Ca}, \mathrm{Mg}$ and $\mathrm{Zn}$. One factor that complicates dietary assessment in active individuals such as military personnel includes high energy consumption, which is required to meet the elevated needs of occupational activity. Individuals with high energy intakes may meet nutrient reference values more easily because of this increased food consumption, but may not consume diets consistent with dietary guidelines. Alternative approaches to dietary assessment may therefore be a more effective means of not only assessing the quality of diet intake in these populations but also for examining the relationship between dietary intake and nutrition knowledge ${ }^{(14)}$.

Recently, an Australian Recommended Food Score (ARFS) was developed to evaluate diet quality within the Australian population $^{(26)}$. The ARFS, modelled on the Recommended Food Score developed by Kant \& Thompson ${ }^{(27)}$, is derived primarily from dietary intakes measured by an Australian $\mathrm{FFQ}^{(28)}$. The ARFS is known to be influenced by demographic factors including age, self-related health status, level of physical activity and education ${ }^{(26)}$. Studies thus far limited to female cohorts have found that a higher ARFS is associated with positive dietary attributes including frequent consumption and greater variety of vegetables, fruits, whole-grains, nuts, legumes, meats and reduced-fat dairy products ${ }^{(26)}$. A higher ARFS is also associated with a lower frequency intake of foods considered unhealthy ${ }^{(26)}$.

Adequate nutrition is a key component of operational readiness for military personnel. Although various approaches exist to influence military personnel dietary habits, interventions to increase knowledge are often the primary approach. The aim of this study was to evaluate the relationship between nutrition knowledge and dietary intake in an Australian military sample using a well-validated tool to assess nutrition knowledge ${ }^{(29,30)}$ and the $\mathrm{ARFS}^{(26)}$ to assess diet quality. The present study also aimed to examine the association and underlying demographic factors linking nutrition knowledge and diet quality in this population.

\section{Methods}

Participants and study design

A convenience sample of male Australian Regular Army personnel participated in this study. To ensure a cross-section of occupations and ranks, personnel were invited to participate from both Brigade (field-based) and Headquarter (desk-based) environments. Participants completed a general nutrition knowledge questionnaire (GNKQ) and FFQ administered via 'paper and pencil' or online, depending on participant computer access. Demographic information collected included the following: sex, age, level of education, living arrangement (family $v$. non-family arrangement), living environment (live on base $v$. off base), rank, self-rated nutrition knowledge and previous nutrition education at school or during military service. Two specific questions on eating patterns were also included. The first examined how often during an average week (including weekends) participants skipped breakfast, lunch and/or dinner. Response options included 'always', 'often', 'sometimes' or 'never'. The second examined on average how many times per week participants ate dinner away from home - for example, from a restaurant, takeaway or frontline (military canteen). Participants were required to provide a numerical value of occasions per week. This study was conducted according to the guidelines laid down in the Declaration of Helsinki and was approved by the Australian Defence Human Research Ethics Committee. The National Statement on Ethical Conduct in Human Research (developed jointly by the National Health and Medical Research Council, Australian Research Council and the Australian Vice Chancellors Committee, March 2007) has been adhered to. Written informed consent was obtained from all participants before participation.

\section{General nutrition knowledge questionnaire}

The GNKQ and local adaptations have been previously used in a number of Western populations ${ }^{(9,10,31-33)}$ including Australian cohorts $^{(11,34)}$. The GNKQ has also been psychometrically validated $^{(29,30,34)}$ and is designed to measure a spectrum of nutrition knowledge (content validity), including dietary guideline recommendations (Section $\mathrm{A}$ ), nutrient content of foods (Section B), everyday food choice (Section C) and links between diet and disease (Section D). When administered to cohorts with varying degrees of nutrition knowledge, significantly different scores are achieved (construct validity). Internal consistency and test-re-test reliability of the GNKQ have also been conducted ${ }^{(34,35)}$. Minor modifications that have been subsequently validated were made to the original GNKQ for the Australian population, for example, the use of Australian terminology, resulting in a maximum of 113 points compared with the original version, which contained 110 points ${ }^{(30)}$. 


\section{Assessment of dietary intake}

Dietary intake was assessed using the Dietary Questionnaire for Epidemiology Studies (DQES) version 2, a FFQ developed and validated by Cancer Council Victoria ${ }^{(28)}$. The DQES is designed to measure usual intake over the preceding 12-month period, including the frequency of seventy-four food items and six alcoholic beverages using a 10-point frequency scale. The food items are grouped into four categories: cereal foods, sweets and snacks; dairy products, meat and fish; fruits; and vegetables. Additional questions about the number of serves of different types of fruits, vegetables, bread, dairy products, eggs, fat spreads and sugar are used to probe diet quality. The DQES has been validated in a number of cohorts and performs well against numerous other dietary assessment methods ${ }^{(26)}$.

\section{Diet quality and Australian Recommended Food Score}

The ARFS was used to assess diet quality from FFQ data. The ARFS was originally modelled on the recommended food score (RFS) by Kant \& Thompson ${ }^{(27)}$ and re-modelled by Collins et $a l^{(26)}$. This tool is intended to measure the frequency of consumption of foods independent of amounts owing to the associated measurement error with amounts. The ARFS is based on the nutrition and dietary recommendations from the Dietary Guidelines for Australian Adults ${ }^{(36)}$ and The Australian Guide to Healthy Eating ${ }^{(37)}$. The maximum possible score is 74 . For more detailed information on ARFS scoring, refer to the study by Collins et al. ${ }^{(26)}$. Previous studies that utilised similar scores, that is RFS and Alternate Healthy Eating Index, applied this same $\operatorname{method}^{(27,38-40)}$.

\section{Statistical analysis}

$\chi^{2}$ Tests for homogeneity were used to compare officers and soldiers with regard to categorical demographic variables (age groups, education), rank and whether the military personnel lived in a family environment. Two sample $t$ tests were used to compare the GNKQ total score and sub-section scores for officers and soldiers. To adjust for demographic variables, ANCOVA were used to compare GNKQ total and sub-section scores for officers and soldiers. For meat/poultry, fish, fats and alcohol ARFS component scores, Fisher's exact $\chi^{2}$ was used to compare officers and soldiers, whereas the median test was used for vegetables, fruit, grains, eggs/nuts/beans/soya and dairy ARFS component scores. To adjust ARFS component scores for demographic variables and total GNKQ score, ordinal logistic regressions were used. The strength of a relationship between two quantitative variables is reported using Spearman's rank correlation coefficient. Data are reported as mean values and standard deviations; significance was set at $P<0.05$.

\section{Results}

\section{Participant characteristics}

In all, 211 male military personnel ranging in rank from Private (lowest) to Colonel (highest) participated in this study (Table 1).
The mean age of the participants was 28.7 (SD 8.9) years. The group consisted predominantly of junior soldiers (Private, Corporal and Lance Corporal) (78.2\%), senior soldiers (Sergeants and Warrant officers) (9.5\%) and officers (12.3\%). Most participants were from Combat Arms, for example, infantry, armoured and artillery (60.5\%), Combat Service Support, for example, ordinance, cooks, medics and transport (23.2\%), and Combat Support, for example, engineers (16.3\%). The majority lived off base $(74.4 \%)$, with approximately half of the total sample living with their families (55.0\%). Most of the participants self-rated their nutrition knowledge as average $(67.5 \%)$, with a smaller number rating their nutrition knowledge as above (22.5\%) or below average (10.0\%). A substantial proportion reported previous nutrition education throughout school (61.1\%) and/or throughout their military service $(51.9 \%)$. A large proportion of participants reported never skipping breakfast (43.6\%), with others skipping sometimes $(32.2 \%)$, often $(19.0 \%)$ or always (5.2\%). In addition, $16 \cdot 4 \%$ of participants reported eating their evening meal from a restaurant, takeaway or Frontline $\geq 3$ times/week.

\section{General nutrition knowledge scores}

The mean GNKQ score was $52.7 \%$ (Table 2). Overall, participants scored the highest $(58.5 \%)$ on Section A (knowledge of dietary recommendations) and the lowest (31.0\%) on Section D (diet-disease relationships). When considering rank, officers scored significantly higher than soldiers overall $(P=0 \cdot 001)$, as well as for Section B (sources of nutrients; $P=0.009$ ) and D (diet-disease relationships; $P=0 \cdot 001$ ). They also scored nonsignificantly higher for Section A (knowledge of dietary recommendations; $P=0 \cdot 259$ ) and Section $C$ (choosing everyday foods; $P=0 \cdot 130)$. The highest scoring sections by rank were Section B (63.1\%) for officers and Section A (58.5\%) for soldiers. Both groups scored the worst on Section D (officers: $39.5 \%$, soldiers: $30 \cdot 0 \%$ ).

When adjusting for potential confounders, age was the only demographic characteristic significantly associated with the GNKQ total score $(P<0.0005)$ and three of the four sub-section GNKQ scores (A: $P=0.069$, B: $P=0.003$, C: $P=0 \cdot 005$, D: $P=0 \cdot 027$ ). Age was significantly and weakly, positively correlated to the overall ( $r$ 0.307; $P<0 \cdot 0005)$ and all sub-section GNKQ scores (A: $r 0 \cdot 140$, $P=0.042$; B: $r 0.279, P<0.0005$; C: $r 0.178, P=0.010$; D: $r 0 \cdot 272$; $P<0.0005)$ but only explained $25.4 \%$ of the variance for the overall GNKQ score. No significant associations were observed for any of the other demographic characteristics (e.g. level of education, living arrangement).

The effect of self-rated nutrition knowledge ('below average', 'average', 'above average') was also evaluated. Personnel who selfrated their nutrition knowledge as 'above average' (mean GNKQ: 58.5 (SD 10.9) \%) scored significantly higher $(P<0.0005)$ than those who self-rated as 'average' (mean GNKQ: 52.4 (SD 9.8\%) or 'below average' (mean GNKQ: 42.9 (SD 9.9)\%). Self-rated nutrition knowledge explained $13.8 \%$ of the variance in the overall GNKQ score. Previous nutrition education in the Army had no significant influence on the overall GNKQ score $(P=0 \cdot 109)$. Regarding meal skipping and eating outside home, participants 
Table 1. Participant demographic characteristics

(Numbers and percentages; mean values and standard deviations)

\begin{tabular}{|c|c|c|c|c|c|c|c|}
\hline \multirow[b]{2}{*}{ Characteristics } & \multicolumn{2}{|c|}{ All $(n 211)(100 \cdot 0 \%)$} & \multicolumn{2}{|c|}{ Officers ( $n 26)(15.5 \%)$} & \multicolumn{2}{|c|}{ Soldiers ( $n$ 185) $(84.5 \%)$} & \multirow[b]{2}{*}{$P^{*}$} \\
\hline & $n$ & $\%$ & $n$ & $\%$ & $n$ & $\%$ & \\
\hline \multicolumn{8}{|l|}{ Age (years) } \\
\hline Mean & \multirow{2}{*}{\multicolumn{2}{|c|}{$\begin{array}{r}28.7 \\
8.9\end{array}$}} & \multirow{2}{*}{\multicolumn{2}{|c|}{$\begin{array}{l}39.4 \\
10.2\end{array}$}} & \multirow{2}{*}{\multicolumn{2}{|c|}{$\begin{array}{r}27 \cdot 2 \\
7 \cdot 6\end{array}$}} & $<0.0005$ \\
\hline SD & & & & & & & \\
\hline $18-24$ & 100 & $47 \cdot 4$ & 3 & 11.5 & 97 & 52.4 & $<0.0005$ \\
\hline $25-34$ & 63 & 29.9 & 5 & $19 \cdot 2$ & 58 & 31.4 & $<0.0005$ \\
\hline$>34$ & 48 & $22 \cdot 7$ & 18 & $69 \cdot 2$ & 30 & $16 \cdot 2$ & 0.111 \\
\hline Level of education & & & & & & & $<0.0005$ \\
\hline High school† & 141 & $66 \cdot 8$ & 1 & $3 \cdot 8$ & 140 & $75 \cdot 7$ & $<0.0005$ \\
\hline Tertiary $\ddagger$ & 70 & $32 \cdot 3$ & 25 & $96 \cdot 2$ & 45 & $24 \cdot 3$ & 0.022 \\
\hline Rank & & & & & & & $<0.0005$ \\
\hline Commissioned officer & 26 & $12 \cdot 3$ & 26 & $100 \cdot 0$ & & & \\
\hline Sergeant to warrant officer & 20 & 9.5 & & & 20 & $10 \cdot 8$ & \\
\hline Private to Corporal & 165 & $78 \cdot 2$ & & & 165 & $89 \cdot 2$ & \\
\hline Living arrangement & & & & & & & 0.532 \\
\hline Family§ & 116 & $55 \cdot 0$ & 14 & $53 \cdot 8$ & 102 & $55 \cdot 1$ & \\
\hline Non-family\|l & 95 & $45 \cdot 0$ & 12 & $46 \cdot 2$ & 83 & 44.9 & \\
\hline Live on base & & & & & & & 0.004 \\
\hline Yes & 54 & $25 \cdot 6$ & 1 & 3.8 & 53 & $28 \cdot 6$ & \\
\hline No & 157 & 74.4 & 25 & $96 \cdot 2$ & 132 & 71.4 & \\
\hline Self-rated nutrition knowledge & & & & & & & 0.027 \\
\hline Above average & 47 & 22.5 & 11 & $42 \cdot 3$ & 36 & $19 \cdot 6$ & 0.010 \\
\hline Average & 141 & 67.5 & 13 & $50 \cdot 0$ & 128 & $70 \cdot 0$ & $0 \cdot 110$ \\
\hline Below average & 21 & $10 \cdot 0$ & 1 & 3.8 & 20 & $10 \cdot 9$ & 0.480 \\
\hline Previous nutrition education at school & & & & & & & 0.001 \\
\hline Yes & 129 & $61 \cdot 1$ & 8 & $30 \cdot 8$ & 121 & $65 \cdot 4$ & \\
\hline No/not sure & 82 & $38 \cdot 9$ & 18 & $69 \cdot 2$ & 64 & 34.6 & \\
\hline Previous nutrition education in Army & & & & & & & 0.005 \\
\hline Yes & 109 & $51 \cdot 9$ & 6 & $24 \cdot 0$ & 103 & $55 \cdot 7$ & \\
\hline No/not sure & 101 & $48 \cdot 1$ & 19 & $76 \cdot 0$ & 82 & $44 \cdot 3$ & \\
\hline Skips breakfast & & & & & & & 0.651 \\
\hline Never & 92 & $43 \cdot 6$ & 9 & $34 \cdot 6$ & 83 & 44.9 & 0.400 \\
\hline Sometimes & 68 & $32 \cdot 2$ & 11 & $42 \cdot 3$ & 57 & $30 \cdot 8$ & 0.266 \\
\hline Often & 40 & $19 \cdot 0$ & 5 & $19 \cdot 2$ & 35 & $18 \cdot 9$ & 1.000 \\
\hline Always & 11 & $5 \cdot 2$ & 1 & $3 \cdot 8$ & 10 & $5 \cdot 4$ & 1.000 \\
\hline Skips lunch & & & & & & & 0.038 \\
\hline Never & 134 & 63.5 & 11 & $42 \cdot 3$ & 123 & $66 \cdot 5$ & 0.028 \\
\hline Sometimes & 72 & 34.1 & 14 & $53 \cdot 8$ & 58 & 31.4 & 0.028 \\
\hline Often & 5 & $2 \cdot 4$ & 1 & $3 \cdot 6$ & 4 & $2 \cdot 2$ & 0.485 \\
\hline Always & 0 & 0 & 0 & 0.0 & 0.0 & 0.0 & 1.000 \\
\hline Skips dinner & & & & & & & 1.000 \\
\hline Never & 176 & $83 \cdot 4$ & 22 & $84 \cdot 6$ & 154 & $83 \cdot 2$ & 1.000 \\
\hline Sometimes & 33 & $15 \cdot 6$ & 4 & $15 \cdot 4$ & 29 & $15 \cdot 7$ & 1.000 \\
\hline Often & 1 & 0.5 & 0 & 0.0 & 1 & 0.5 & 1.000 \\
\hline Always & 1 & 0.5 & 0 & 0.0 & 1 & 0.5 & 1.000 \\
\hline
\end{tabular}

* Baseline categorical data analysed by $\chi^{2}$ test for homogeneity (except age: analysed by two sample $t$ test), significance set at $P<0.05$.

$\dagger$ Includes participants in the final 4 years of high school, year 8-12 (14-18 years).

$\ddagger$ Includes TAFE, university, private college.

$\S$ Includes living with partner/spouse and/or children.

II Includes living alone/with peers/flat mates/on base.

who reported never skipping breakfast (43.6\%) scored significantly higher overall and in Section B and Section D of the GNKQ score than those who skipped breakfast sometimes, often or always (56.4\%) (Overall $56 \cdot 2$ v. 51.2\%, $P=0 \cdot 001 ;$ A: $60 \cdot 8$ v. $57 \cdot 8 \%$, $P=0.174 ; \mathrm{B}: 60.8$ v. $55.6 \%, P=0.004 ; \mathrm{C}: 58.9$ v. $55 \cdot 0 \%, P=0.308$; D: $35.2 v .29 .9 \%, P=0.019)$. Those who ate their evening meal outside home $\geq 3$ times a week (16.4\%) had significantly lower GNKQ scores than those reporting they did this $<3$ times a week (Overall $47.6 v$. 54.6\%, $P=0.000$; A: $51.8 v$. $60.8 \%, P=0.003$; B: 52.9 v. $58.9 \%, P=0.006$; C: 50.3 v. $58.0 \%, P=0.014 ; \mathrm{D}: 25.7 v$. $33.5 \%, P=0.003)$. No significant associations were found for skipping other meals.

\section{Australian Recommended Food Score}

The average ARFS of the entire cohort was $37 \cdot 6$ (SD 7.7) (50.8\%) (Table 3). Demographic factors such as age, level of education and living arrangement were not significantly associated with total ARFS. However, officers achieved a significantly higher total ARFS than soldiers (officers: 40.5 (SD 8.0), 54.7\% $v$. soldiers: $37 \cdot 2$ (sD 7.6), 50.3\%; $P=0 \cdot 040$ ). Officers also achieved a non-significantly higher sub-component ARFS for vegetables, fruits, grains, meat/poultry, fish, dairy products and fats, with scores being similar for protein foods (eggs/nuts/beans/soya). Officers also had a better score for alcohol than soldiers 
Table 2. Nutrition knowledge scores on the general nutrition knowledge questionnaire

(Mean values, standard deviations, percentages and $95 \%$ confidence intervals)

\begin{tabular}{|c|c|c|c|c|c|c|c|c|c|c|c|c|c|c|}
\hline \multirow[b]{2}{*}{ Knowledge domain } & \multicolumn{4}{|c|}{ All scores $(n 211)$} & \multicolumn{4}{|c|}{ Officers scores $(n$ 26) } & \multicolumn{4}{|c|}{ Soldiers scores $(n 185)$} & \multirow[b]{2}{*}{$P^{*} \dagger$} & \multirow[b]{2}{*}{$P^{*} \ddagger$} \\
\hline & Mean & SD & $\%$ & $95 \% \mathrm{Cl}$ & Mean & SD & $\%$ & $95 \% \mathrm{Cl}$ & Mean & SD & $\%$ & $95 \% \mathrm{Cl}$ & & \\
\hline A: dietary recommendations (13 point total) & 7.6 & 2.2 & 58.5 & $7 \cdot 3,7.9$ & $8 \cdot 0$ & 1.7 & 61.5 & $7 \cdot 3,8.7$ & 7.6 & $2 \cdot 3$ & 58.5 & $7 \cdot 2,7 \cdot 9$ & 0.259 & 0.844 \\
\hline B: sources of nutrients (70 point total) & 40.1 & 8.6 & $57 \cdot 3$ & $39 \cdot 0,41 \cdot 3$ & $44 \cdot 2$ & $9 \cdot 6$ & $63 \cdot 1$ & $40 \cdot 3,48 \cdot 1$ & 39.4 & 8.3 & $56 \cdot 3$ & $38.4,40.8$ & 0.009 & 0.268 \\
\hline C: choosing every day foods (10 point total) & $5 \cdot 7$ & 1.8 & $57 \cdot 0$ & $5 \cdot 4,5 \cdot 9$ & $6 \cdot 2$ & $2 \cdot 0$ & $62 \cdot 0$ & $5.4,6.9$ & $5 \cdot 6$ & 1.7 & $56 \cdot 0$ & $5.3,5.9$ & 0.130 & 0.986 \\
\hline D: diet-disease relationship (20 point total) & $6 \cdot 2$ & 2.8 & $31 \cdot 0$ & $5 \cdot 9,6 \cdot 6$ & 7.9 & $2 \cdot 8$ & 39.5 & $6.8,9.0$ & $6 \cdot 0$ & 2.7 & $30 \cdot 0$ & $5 \cdot 6,6 \cdot 4$ & 0.001 & 0.103 \\
\hline Total knowledge score (113 point total) & $59 \cdot 6$ & $12 \cdot 2$ & $52 \cdot 7$ & $58 \cdot 0,61 \cdot 3$ & $66 \cdot 3$ & 13.1 & 58.7 & $61 \cdot 0,71 \cdot 6$ & 58.7 & $11 \cdot 8$ & 51.9 & $57 \cdot 0,60 \cdot 4$ & 0.001 & 0.210 \\
\hline
\end{tabular}

* Significant difference set at $P<0.05$

† $P$-value comparison between officer and soldier group means - differences assessed using ANCOVA.

$\ddagger$ Adjusted $P$-value for general linear model with predictors age, education, living arrangement.

Table 3. Australian Recommended Food Scores (ARFS)

(Mean values, standard deviations and percentages)

\begin{tabular}{|c|c|c|c|c|c|c|c|c|c|c|}
\hline \multirow[b]{2}{*}{ Component score (maximum score) } & \multicolumn{3}{|c|}{ All $(n 211)$} & \multicolumn{3}{|c|}{ Officers $(n 26)$} & \multicolumn{3}{|c|}{ Soldiers ( $n$ 185) } & \multirow[b]{2}{*}{$P^{\star}$} \\
\hline & Mean & $\mathrm{SD}$ & $\%$ & Mean & SD & $\%$ & Mean & $\mathrm{SD}$ & $\%$ & \\
\hline Vegetables (22) & $16 \cdot 7$ & 3.9 & 75.9 & $18 \cdot 2$ & 3.5 & $82 \cdot 7$ & 16.5 & 4.0 & $75 \cdot 0$ & 0.182 \\
\hline Fruits (14) & $5 \cdot 3$ & $3 \cdot 2$ & 37.9 & 5.4 & 3.0 & 38.6 & $5 \cdot 3$ & $3 \cdot 2$ & 37.9 & 0.334 \\
\hline Grains (14) & 4.5 & 1.9 & $32 \cdot 1$ & $5 \cdot 0$ & $2 \cdot 0$ & $35 \cdot 7$ & 4.4 & 1.9 & 31.4 & 0.392 \\
\hline Eggs/nuts/beans/soya (7) & $2 \cdot 4$ & 1.0 & 31.4 & $2 \cdot 4$ & $1 \cdot 1$ & $34 \cdot 3$ & 2.4 & 1.0 & 34.3 & 0.513 \\
\hline Meat/poultry (5) & 3.5 & 1.3 & $70 \cdot 0$ & 3.6 & 1.2 & $72 \cdot 0$ & 3.5 & 1.3 & $70 \cdot 0$ & 0.988 \\
\hline Fish (2) & 1.3 & 0.8 & $65 \cdot 0$ & 1.4 & 0.7 & $70 \cdot 0$ & 1.3 & 0.8 & $65 \cdot 0$ & 0.754 \\
\hline Dairy products (7) & $2 \cdot 2$ & $1 \cdot 1$ & 31.4 & 2.5 & $1 \cdot 1$ & $35 \cdot 7$ & $2 \cdot 2$ & $1 \cdot 1$ & 31.4 & 0.623 \\
\hline Fats (1) & 0.5 & 0.5 & $50 \cdot 0$ & 0.7 & 0.5 & $70 \cdot 0$ & 0.5 & 0.5 & $50 \cdot 0$ & 0.094 \\
\hline Alcohol (2) & 1.1 & 0.5 & $55 \cdot 0$ & 1.3 & 0.5 & $65 \cdot 0$ & 1.0 & 0.5 & $50 \cdot 0$ & 0.011 \\
\hline ARFS Total (74) & 37.6 & $7 \cdot 7$ & $50 \cdot 8$ & 40.5 & 8.0 & $54 \cdot 7$ & $37 \cdot 2$ & $7 \cdot 6$ & 50.3 & 0.040 \\
\hline
\end{tabular}

* Differences between officer and soldier group means. Significant difference set at $P<0.05$. 
( $P=0.011$ ), indicating an intake more consistent with the Australian recommendations for alcohol consumption ${ }^{(41)}$. The only demographic factor significantly associated with sub-section ARFS was living in a family environment (as opposed to living alone), which resulted in a better ARFS for fat $(P=0.028)$. With respect to skipping breakfast, those who never skipped breakfast (43.6\%) scored significantly higher total ARFS than those who skipped breakfast sometimes, often or always (56.4\%) (ARFS: 53.7 v. 49.1\%, $P=0.001$ ). No significant associations were found for skipping other meals. No significant differences in ARFS were observed between those who ate their evening meal outside home $\geq 3$ times a week $v .<3$ times/week.

The total GNKQ score had a significant, positive but weak relationship with total ARFS $(r 0.179 ; P=0.009)$ and explained $3.8 \%$ of the variance. For every 10 -point increase in GNKQ, ARFS increased by 1.4 points $(P=0 \cdot 001)$. With respect to ARFS component scores, a significant, positive but weak correlation was found for GNKQ total score and the sub-component ARF score for vegetables $(r 0 \cdot 23 ; P=0 \cdot 001)$ and dairy products ( $r$ 0.20; $P=0.004$ ). The mean GNKQ score was also higher ( $54.5 v .51 \cdot 2 \%$ ) for participants scoring ' 1 ' $v$. ' 0 ' for the fat sub-component of ARFS $(P=0.038)$. There were no other significant correlations between GNKQ total score and sub-component scores of the ARFS

\section{Discussion}

This is the first study to investigate the relationship between nutrition knowledge and dietary intake in military personnel. The overall nutrition knowledge score in this study was similar to an Australian community sample of men ${ }^{(11)}$. Although officers were found to have significantly higher nutrition knowledge than soldiers, this was still below mixed-sex, Australian community samples ${ }^{(30,34)}$. Overall performance on the different knowledge domains was similar to most other studies using the same instrument, with participants performing best on knowledge of dietary guidelines and worst on diet-disease relationships ${ }^{(11,29,30)}$. Age was the only demographic factor significantly influencing nutrition knowledge. The diet quality of both soldiers and officers in this cohort was relatively low, although slightly higher than that reported by a large study of Australian women ${ }^{(26)}$, which also used the ARFS. As with nutrition knowledge, officers had significantly higher overall diet quality than soldiers. The relationship between nutrition knowledge and diet quality was found to be significant, positive but weak, consistent with the findings reported by a recent systematic review ${ }^{(18)}$. Initiatives to improve nutrition knowledge and encourage healthy eating, particularly in soldiers, are warranted.

The overall GNKQ score in this study was $52.7 \%$, which was below the recently reported data from Australian, mixed-sex community $(64.1 \%)^{(30)}$ and athlete samples $(57.6 \%)^{(34)}$ who also completed the GNKQ. Although it might be expected that military personnel would have better nutrition knowledge because of the link between diet and physical performance, this study indicates that nutrition knowledge at least in male soldiers is similar to a cohort of Australian men $(52 \cdot 8 \%)^{(11)}$, suggesting that higher scores in mixed-sex groups are driven by better nutrition knowledge in women, a finding often reported in other cohorts internationally ${ }^{(9-13)}$. Historically, women have assumed the major responsibility for household food provision ${ }^{(9)}$, a role which nurtures better nutrition knowledge $^{(11)}$. Nutrition education in the Australian military is generally limited to a 1-h lecture and a short dining hall orientation delivered during the early recruitment training period. There is minimal progressive or occupation-specific nutrition education, and this is the most likely reason for the levels of nutrition knowledge being similar to the community. In contrast to previous studies ${ }^{(9,10,13,16,42)}$, there was no effect of rank, level of education or living arrangement on nutrition knowledge in this study. In fact, the best predictor of nutrition knowledge was self-rated competency, with those self-rating nutrition knowledge 'above average' achieving significantly higher scores on the GNKQ than those who self-rated nutrition knowledge as 'below average'.

Performance on sub-sections of the GNKQ revealed a pattern consistent with other studies using the same tool ${ }^{(10,11,29,30,31,34)}$, with the sample performing the best on Section A (dietary recommendations) and the worst on Section D (diet-disease relationships). Better performance on Section A may be due to current dietary guideline messages (e.g. eat less fat, eat more fibre) being frequently disseminated in the media and community in general. The scores on Section D (diet-disease relationships) in this study were particularly low (31.0\%) in comparison with other Australian community and athlete groups (range: 35.0-50.0\%) ${ }^{(11,30,34)}$; however, they were similar to that of a UK study of predominantly male university students $(31 \cdot 0 \%)^{(29)}$. Lower scores for this section are consistently reported across studies. Given that the majority of this military sample was relatively young, with $47.4 \%$ under the age of 25 years, it may be that the relationship between diet and disease seems less relevant to the participants at this life stage. Section D (diet-disease relationships) was also the only openended section requiring participants to respond in writing rather than via multiple choice, potentially making this section more challenging to answer and/or may have resulted from response fatigue as this part of the instrument is completed last. The scores on Section B and C were similar to those of other Australian men ${ }^{(11)}$. Section $\mathrm{C}$ focused on procedural knowledge (i.e. 'how to' plan, purchase and prepare healthy food). In the present study, both officers and soldiers scored higher than Australian men, but substantially lower than mixed-sex community groups on this section. This type of food knowledge is important for understanding how to choose healthier options when presented with a wide range of foods; therefore, finding ways to focus more on this type of knowledge may be key in changing behaviour.

Although it might be expected for military personnel who are required to maintain occupational physical fitness standards to have high-quality diets, the mean total AFRS in this military sample was low (50.8\%). Although officers achieved a significantly higher total ARFS than soldiers (officers: $40 \cdot 5$ (sD 8.0), 54.7\% $v$. soldiers: $37 \cdot 2$ (SD 7.6), 50.3\%; $P=0 \cdot 040$ ), their scores also remained low. The low total ARF scores in this study were mostly attributed to a lack of variety and inadequate intake of fruits and vegetables, low consumption of high-fibre 
breads and cereals, poor intake of low-fat dairy foods, higher than recommended consumption of alcohol and dietary fat intakes inconsistent with dietary guidelines. Studies using the ARFS in Australia have been in female cohorts ${ }^{(26,43-45)}$, making it difficult to compare our results, given that the present study was an all-male sample. However, the Australian National Nutrition Survey identified the diets of young men in particular to follow a similar pattern of low fruit and vegetable intake and high levels of alcohol consumption ${ }^{(46)}$. This pattern was also shown in a group of young Australian male athletes using an adapted version of the ARFS, with the diets of male athletes inferior to their female counterparts ${ }^{(47)}$. The only factors significantly associated with total ARFS and sub-section ARFS in this study were breakfast consumption and living in a family environment. This is in contrast with previous studies using healthy eating index approaches ${ }^{(48-50)}$, which have found age and education to be associated with higher diet-quality scores, but consistent with research that indicates skipping breakfast to be associated with poor nutrient intake and diet quality and associated weight gain ${ }^{(22)}$. It is possible that the lack of association between demographic factors such as education and diet quality was due to the limited power to assess this because of the smaller number of officers than soldiers. With regard to breakfast skipping, military personnel are required to participate in physical training on arrival at work most days of the week. Possible explanations for skipping breakfast could therefore be time constraints, individual preference to not perform physical activity on a full stomach and inflexible dining facility hours to enable post-training breakfast consumption.

This study found a significant relationship between general nutrition knowledge (GNKQ score) and diet quality (ARFS). A recent systematic review from our group ${ }^{(18)}$ also found either null or weak $(r<0.5)$ relationships when examining this relationship. ARFS component scores for vegetables, dairy products and fat in this study were significantly correlated with GNKQ scores and the relationship was weakly positive. Other studies using the same GNKQ have also reported a positive relationship between nutrition knowledge and intakes of vegetables as well as fruits, fibre, fish and low-fat products $^{(10,31,32,33)}$. Similarly, significant relationships between general nutrition knowledge and dairy ${ }^{(51,52)}$ and fat ${ }^{(53)}$ intakes have been observed by studies examining nutrition knowledge utilising other general knowledge questionnaires.

Numerous theoretical models have been developed to better understand eating behaviour ${ }^{(54)}$. These models hypothesise that health behaviours (e.g. food choice) are determined by individual, social and environmental factors such as one's ability to make healthy choices, their motivation to do so and environmental opportunities ${ }^{(7,8)}$. One of the earliest models that would seem pertinent to this study is the knowledgeattitude-behaviour (KAB) model. The KAB model is based on the hypothesis that an increase in nutrition knowledge improves attitudes towards healthy eating and subsequently improves eating behaviour ${ }^{(54)}$. However, given the weak relationship found between nutrition knowledge and diet quality observed in this study, it appears that this model has limited capacity to predict eating behaviour in male military personnel.
More recently, social ecological models of behaviour have been used to explain eating behaviour in military populations ${ }^{(55)}$. These models move beyond just intrapersonal factors and emphasise interpersonal (e.g. peer and family influences) and environmental factors on eating behaviour ${ }^{(56)}$, which may have greater application to the unique military setting. For example, military personnel spend a substantial proportion of their career away from the home environment, with many living in shared accommodation facilities on base; thus, the influence of military peers and the physical eating environment in barracks (e.g. the dining hall) and in the field (e.g. combat ration packs) have the potential to influence eating attitudes and behaviours. In terms of the physical environment (i.e. availability of healthy and unhealthy choices), restricted or inappropriate menus provided on Army bases were unlikely to have been a contributing factor to the low ARFS, given that $>50 \%$ of personnel never consume meals in the mess. On average, only $10.0 \%$ of military personnel reported eating $\geq 15$ meals (i.e. breakfast or lunch or dinner) in the mess during a 7 -d week (Kullen unpublished results). However, difficulty accessing the dining facilities due to inflexible operating hours may have influenced personnel to seek more convenient but potentially unhealthier food options elsewhere.

From a practical perspective, recruitment into the military from a young age and/or directly from the family home where meals may have been prepared by others may limit exposure to practical skills such as shopping for and cooking food, a factor shown to be associated with increased consumption of fast food $^{(57)}$. In addition, research examining factors that influence food selection in young people have found taste to be the most important influence, followed by convenience (availability), cost and then nutritional/health value of the food ${ }^{(58)}$. Noting the age of the study population, it is possible that these factors may explain to some extent the present diet-quality scores.

Eating, drinking and making food choices are some of the most frequent human behaviours. Although seemingly simple, a complex web of personal, social and environmental factors influence these behaviours ${ }^{(59)}$. Future research therefore needs to better understand the aspirations of military personnel regarding their health, fitness and food-related goals, how they acquire food-related knowledge and what social and environmental factors need to be considered when designing future nutrition initiatives. The potential for social ecological models and other recognised behavioural change models such as the Health Belief Model, Social Cognitive Theory and Theory of Planned Behaviour therefore warrant further investigation in military populations, as little research currently exists in the area of eating behaviour. Future research of this type will, however, need to ensure that the behaviours being tested are within the person's control (e.g. healthy food choices will need to be available in the dining facility).

Although some nutrition education is likely central to the success of these models, single-factor interventions focusing on just knowledge or just the food service environment are unlikely to be effective in positively changing eating behaviour. The military setting does, however, provide a unique environment in which nutrition education and dietary interventions can embrace a multidisciplinary approach. Opportunities exist for traditional methods (e.g. seminars, face-to-face workshops), 
practical skill development (e.g. cooking lessons), but also potentially for novel approaches using technology such as web or smart phone applications. There is also significant potential to exploit passive interventions such as food labelling and social marketing at points of food service. Clearly the interventions need to go beyond improving nutrition knowledge as the relationship with diet quality is weak.

Strengths of this present study include the use of validated tools to assess general nutrition knowledge and diet quality. The study makes a useful contribution to the limited body of literature in this area and is the first to determine the relationship between nutrition knowledge and diet quality in a military population. The present sample was of moderate size but sufficiently large to find significant associations between nutrition knowledge and diet quality and also assess differences between officer and soldier sub-groups. However, larger military samples with a wider range of nutrition knowledge may be needed to more comprehensively assess the strength of the associations reported in this study. Most importantly, our results cannot be generalised to female military personnel. Although females form a small part of the Australian military (approximately 10-15\%), evidence from one study in military personnel ${ }^{(13)}$ demonstrates that women have superior dietary intake/diet quality.

In conclusion, this study demonstrates a positive, weak relationship between nutrition knowledge and diet quality in military personnel. Despite officers achieving higher nutrition knowledge and diet-quality scores than soldiers, this study shows that many young male military personnel have limited nutrition knowledge. It also demonstrates that their diets are lacking in variety and many are failing to meet basic dietary guidelines, particularly in relation to fruits, vegetables, grains and dairy products. Military populations provide a unique setting to conduct 'worksite' nutrition interventions; thus, further research in these cohorts, particularly soldiers, who appear to possess lower nutrition knowledge and diet quality is warranted. This study supports the need for well-designed interventions in the Australian military to improve dietary intake. These interventions need to go beyond the provision of nutrition knowledge and should examine the predictive capacity of eating behaviour models to assist in delineating the most effective approach for achieving and maintaining eating behaviour change in this population.

\section{Acknowledgements}

The authors thank the Australian Regular Army personnel who participated in this study, Captain Clay Baker for support during data collection and Laura Iredale for assistance with data collection and data entry. This work was supported by Headquarters Forces Command.

This research received no specific grant from any funding agency, commercial or not-for-profit sectors.

Conception and design (C. J. K., H. T. O'C.), data collection (C. J. K.), data interpretation and analysis (C. J. K., H. T. O'C., T. P., J.-L. F.), writing and editing of the manuscript (C. J. K., H. T. O'C., T. P., J.-L. F.).

The authors declare that there are no conflicts of interest.
The opinions expressed in this research herein are those of the authors and do not necessarily reflect those of Defence or any extant policy.

\section{References}

1. Hill N, Fallowfield J, Price S, et al. (2011) Military nutrition: maintaining health and rebuilding injured tissue. Philos Trans $R$ Soc Lond B Biol Sci 366, 231-240.

2. Tharion WJ, Lieberman HR, Montain SJ, et al. (2005) Energy requirements of military personnel. Appetite $\mathbf{4 4}$, 47-65.

3. Montain SJ, Carvey CE \& Stephens MB (2010) Nutritional fitness. Mil Med 175, 65-72.

4. Worsley A (2002) Nutrition knowledge and food consumption: can nutrition knowledge change food behaviour? Asia Pac J Clin Nutr 11 , Suppl. 6, S579-S585.

5. Glanz K, Basil M, Maibach E, et al. (1998) Why Americans eat what they do: taste, nutrition, cost, convenience, and weight control concerns as influences on food consumption. $J \mathrm{Am}$ Diet Assoc 98, 1118-1126.

6. Bublitz MG, Peracchio LA \& Block LG (2010) Why did I eat that? Perspectives on food decision making and dietary restraint. J Consum Psychol 20, 239-258.

7. Brug J (2008) Determinants of healthy eating: motivation, abilities and environmental opportunities. Fam Pract 25, Suppl. 1, s50-s55.

8. Brug J, Kremers SP, Lenthe FV, et al. (2008) Environmental determinants of healthy eating: in need of theory and evidence. Proc Nutr Soc 67, 307-316.

9. Parmenter K, Waller J \& Wardle J (2000) Demographic variation in nutrition knowledge in England. Health Educ Res 15, 163-174.

10. Wardle J, Parmenter K \& Waller J (2000) Nutrition knowledge and food intake. Appetite 34, 269-275.

11. Hendrie GA, Coveney J \& Cox D (2008) Exploring nutrition knowledge and the demographic variation in knowledge levels in an Australian community sample. Public Health Nutr 11, 1365-1371.

12. Sapp SG \& Jensen HH (1997) Reliability and validity of nutrition knowledge and diet-health awareness tests developed from the 1989-1991 Diet and Health Knowledge Surveys. J Nutr Educ 29, 63-72.

13. Trent LK (1992) Nutrition knowledge of active-duty Navy personnel. J Am Diet Assoc 92, 724-728.

14. Heaney S, O'Connor H, Michael S, et al. (2011) Nutrition knowledge in athletes: a systematic review. Int J Sport Nutr Exerc Metab 21, 248-261.

15. Conway TL, Hervig LK \& Vickers RR Jr (1989) Nutrition knowledge among Navy recruits. J Am Diet Assoc 89, 1624-1628.

16. Bovill M, Tharion $\mathrm{W}$ \& Leiberman $\mathrm{H}$ (2003) Nutrition knowledge and supplement use among elite U.S. army soldiers. Mil Med 168, 997-1000.

17. Ball K, Crawford D \& Mishra G (2006) Socio-economic inequalities in women's fruit and vegetable intakes: a multilevel study of individual, social and environmental mediators. Public Health Nutr 9, 623-630.

18. Spronk I, Kullen C, Burdon C, et al. (2014) Relationship between nutrition knowledge and dietary intake. Br J Nutr 111, 1713-1726.

19. Skiller B, Booth C, Coad A, et al. (2005) Assessment of nutritional status and fatigue among army recruits during the army common recruit training course: part A: catering services and diet. http:// dspace.dsto.defence.gov.au/dspace/handle/1947/4356 (accessed April 2014) 
20. Booth CK \& Coad RA (2002) The 1998 army recruit health and diet survey. Aust Mil Med 11, 63-70.

21. Stark AH, Weis N, Chapnik L, et al. (2008) Dietary intake of pilots in the Israeli Air Force. Mil Med 173, 780-784

22. Smith TJ, Dotson LE, Young AJ, et al. (2013) Eating patterns and leisure-time exercise among active duty military personnel: comparison to the healthy people objectives. J Acad Nutr Diet 113, 907-919.

23. Ramsey CB, Hostetler C \& Andrews A (2013) Evaluating the nutrition intake of U.S. military service members in garrison. Mil Med 178, 1285-1290.

24. Etzion-Daniel Y, Constantini N, Finestone AS, et al. (2008) Nutrition consumption of female combat recruits in army basic training. Med Sci Sports Exerc 40, S677-S684.

25. DeBolt JE, Singh A, Day BA, et al. (1988) Nutritional survey of the US Navy SEAL trainees. Am J Clin Nutr 48, 1316-1323.

26. Collins CE, Young AF \& Hodge A (2008) Diet quality is associated with higher nutrient intake and self-rated health in mid-aged women. J Am Coll Nutr 27, 146-157.

27. Kant A \& Thompson F (1997) Measures of overall diet quality from a food frequency questionnaire: national health interview survey, 1992. Nutr Res 17, 1443-1456.

28. Giles GG \& Ireland PD (1996) Dietary Questionnaire for Epidemiology Studies. Melbourne, VIC: Cancer Council Victoria.

29. Parmenter K \& Wardle J (1999) Development of a general nutrition knowledge questionnaire for adults. Eur J Clin Nutr 53, 298-308.

30. Hendrie GA, Cox D \& Coveney J (2008) Validation of the general nutrition knowledge questionnaire in an Australian community sample. Nutr Diet 65, 72-77.

31. De Vriendt T, Matthys C, Verbeke W, et al. (2009) Determinants of nutrition knowledge in young and middle-aged Belgian women and the association with their dietary behaviour. Appetite 52, 788-792.

32. Gambaro A, Raggio L, Dauber C, et al. (2011) Nutritional knowledge and consumption frequency of foods - a case study. Arch Latinoam Nutr 61, 308-315.

33. Jovanovic GK, Kresic G, Zezelj SP, et al. (2011) Cancer and cardiovascular diseases nutrition knowledge and dietary intake of medical students. Coll Antropol 35, 765-774.

34. Spendlove JK, Heaney SE, Gifford JA, et al. (2012) Evaluation of general nutrition knowledge in elite Australian athletes. $\mathrm{Br} \mathrm{I}$ Nutr 107, 1871-1880.

35. Kline P (2000) The Handbook of Psychological Testing. New York, NY; London: Routledge.

36. National Health and Medical Research Council (2003) Dietary Guidelines for Australian Adults. A Guide to Healthy Eating. Commonwealth of Australia, National Health and Medical Research Council. Canberra: Australian Government Publishing Service.

37. Kellett E, Smith A \& Schmerlaib Y (1998) The Australian Guide to Healthy Eating. Canberra: The Australian Department of Health and Aging.

38. McCullough ML, Feskanich D, Stampfer MJ, et al. (2002) Diet quality and major chronic disease risk in men and women: moving toward improved dietary guidance. Am J Clin Nutr 76, 1261-1271

39. Wirt A \& Collins CE (2009) Diet quality - what is it and does it matter? Public Health Nutr 12, 2473-2492.

40. Guenther PM, Kirkpatrick SI, Reedy J, et al. (2014) The Healthy Eating Index-2010 is a valid and reliable measure of diet quality according to the 2010 Dietary Guidelines for Americans. J Nutr 144, 399-407.

41. National Health and Medical Research Council (2009) Australian guidelines to reduce health risks from drinking alcohol. https://www.nhmrc.gov.au/guidelines/publications/ds10 (accessed April 2014)

42. Obayashi S, Bianchi LJ \& Song WO (2003) Reliability and validity of nutrition knowledge, social-psychological factors, and food label use scales from the 1995 Diet and Health Knowledge Survey. J Nutr Educ Behav 35, 83-92.

43. Collins CE, Patterson A \& Fitzgerald D (2011) Higher diet quality does not predict lower Medicare costs but does predict number of claims in mid-aged Australian women. Nutrients $\mathbf{3}$, 40-48.

44. Aljadani HM, Patterson A, Sibbritt D, et al. (2013) Diet quality, measured by fruit and vegetable intake, predicts weight change in young women. $J$ Obes 2013, 1-10.

45. Aljadani HM, Sibbritt D, Patterson A, et al. (2013) The Australian Recommended Food Score did not predict weight gain in middle-aged Australian women during six years of follow-up. Aust N Z J Public Health 37, 322-328.

46. Australian Institute of Health and Welfare (2012) Australia's Food and Nutrition 2012, AIHW Cat. No. PHE 163. Canberra: AIHW.

47. Spronk I, Heaney SE, Prvan T, et al. (2015) Relationship between general nutrition knowledge and dietary quality in elite athletes. Int J Sport Nutr Exerc Metab 25, 243-251.

48. The United States Department of Agriculture (1995) Centre for Nutrition Policy and Promotion: The Healthy Eating Index. Washington, DC: United States Department of Agriculture. http://www.google.com.au/url?sa=t\&rct=j\&q=\&esrc=s\&source $=$ web\&cd $=4 \& v e d=0 C C 8 Q F j A D a h U K E w j V s t e U n \_3 G A h W m I 6 Y K H$ Tm0A6Q\&url=http\%3A\%2F\%2Fwww.cnpp.usda.gov\%2Fsites\% 2Fdefault\%2Ffiles\%2Fhealthy_eating_index\%2FHEI89-90report. pdf\&ei=Pie3VdWbMKbHmAW5616gCg\&usg=AFQjCNE0IG-oQ NfiyobsGmP4bE0Om_GphA (accessed August 2014).

49. Zarrin R, Ibiebele TI \& Marks GC (2013) Development and validity assessment of a diet quality index for Australians. Asia Pac J Clin Nutr 22, 177-187.

50. Australian Institute of Health and Welfare (2007) Australian Diet Quality Project, AIHW Cat. No. PHE 85. Canberra: AIHW.

51. Guthrie JF \& Fulton LH (1995) Relationship of knowledge of food group servings recommendations to food group consumption. Fam Econ Rev $\mathbf{8}, 2$.

52. Sharma SV, Gernand AD \& Day RS (2008) Nutrition knowledge predicts eating behavior of all food groups except fruits and vegetables among adults in the Paso del Norte region: Que Sabrosa Vida. J Nutr Educ Behav 40, 361-368.

53. Dallongeville J, Marecaux N, Cottel D, et al. (2001) Association between nutrition knowledge and nutritional intake in middleaged men from Northern France. Public Health Nutr 4, 27-33.

54. Baranowski T, Cullen KW, Nicklas T, et al. (2003) Are current health behavioral change models helpful in guiding prevention of weight gain efforts? Obes Res 11, Suppl. 10, s23-s43.

55. Carins J \& Rundle-Thiele S (2014) Fighting to eat healthfully: measurements of the military food environment. J Soc Mark $\mathbf{4}$, 223-239.

56. Sallis JF \& Owen N (2015) Ecological models of health behavior. In Health Behavior: Theory, Research and Practice, 5th ed. pp. 43-64 [K Glanz, B Rimer and K Viswanath, editors]. Hoboken, NJ: Wiley.

57. Thornton LE, Jeffery RW \& Crawford DA (2013) Barriers to avoiding fast-food consumption in an environment supportive of unhealthy eating. Public Health Nutr 16, 2105-2113.

58. Hebden L, Chan HN, Louie JC, et al. (2015) You are what you choose to eat: factors influencing young adults' food selection behaviour. J Hum Nutr Diet 28, 401-408.

59. Köster EP (2009) Diversity in the determinants of food choice: a psychological perspective. Food Qual Prefer 20, $70-82$. 